\title{
Studi Komparasi Karakter Bentuk Estetik Desain Pesawat Tempur F-16 Dan SU-27
}

\author{
Larasmoyo Nugroho
}

Alumni Teknik Penerbangan- Fakultas Teknologi Industri-ITB

\begin{abstract}
Defense and security are serious business, as they represent the integrity and dignity of a nation. It is understandable to assess military power and facilities as crucial to a nation's defense, shown in the use of fighter airplanes. A fighter airplane serves as a window to represent nation's values, philosophy and ideology; appeared through its design form and defense ability. The presented paper explores and compares 2 (two) types of fighter airplane, F16 of US and SU-27 of Russia, in order to observe and characterize their design forms. Having acknowledged the characteristic of their design forms as tangible aspect of analysis, it is identified that this characteristic can be split into form design and numerical design. Comparative assessment of both fighter airplanes indicates that F-16 fighter airplane of US appears smaller than the SU-27 of Russia. The smaller size of F-16 form was meant to have superior maneuverability for air-to-air combat, while the size of SU-27 was meant to accommodate multi-tasking aspects of fighter airplane (air-to-air combat and interceptive act). As results, both airplane forms express different views and ideological perspectives. The F-16 of US shows great and superior ability to carry special task of becoming combat airplane (thrive to perfection), coming with a hefty price and catered for great quality. On the other hand, SU-27 of Russia shows a wider purpose and not necessarily has superior ability in order to carry diverse tasks of an airplane (multi-tasking), coming with a cheaper price and catered in a great quantity. Thus, it can be deduced that the American designer of fighter airplane tends to acknowledge specialization of military purpose compare to the Russian's generalization of military purpose.
\end{abstract}

Keywords: fighter airplane; design characteristic; ideology-driven form.

\section{$1 \quad$ Latar Belakang}

Pesawat tempur merupakan artifak yang dinilai mampu menciptakan rasa aman bagi negara modern saat ini. Menghadapi era perlombaan persenjataan antar negara besar, terutama Amerika Serikat, Rusia, Prancis, Inggris, dan Cina, negara-negara ini bersaing untuk mencapai tingkat keunggulan teknologi.

Secara khusus, dua negara adidaya yang telah lama bersaing dalam teknologi pesawat adalah Amerika dan Rusia. Sebagaimana kita ketahui, Indonesia memiliki dua jenis pesawat tempur yang diproduksi oleh dua negara adidaya itu.

Received September $17^{\text {th }}, 2007$, Revised January $21^{\text {st }}, 2008$, Accepted for publication March $28^{\text {th }}, 2008$ 
Tetapi bagaimanakah karakter dua negara itu dalam menciptakan teknologi canggih? Dengan memahami ideologi dan karakter bangsa yang melatarbelakangi lahirnya sistem persenjataan kedua negara tersebut diharapkan, terjadi pemahaman dalam mengkaji karakter nilai dalam penciptaan sistem persenjataan dilihat dari kacamata budaya.

\section{$2 \quad$ Metoda}

Penelitian difokuskan pada perbandingan 2 jenis pesawat tempur yang dimiliki oleh TNI-AU yaitu pesawat F-16 buatan Amerika Serikat dan Su-27 buatan Rusia. Pemilihan objek telitian ini berdasarkan pertimbangan bahwa peran yang dimiliki pesawat tempur tersebut adalah sebagai air superiority yaitu sebuah peran yang membutuhkan spesifikasi pesawat paling tinggi (khususnya kemampuan bermanuver), serta keduanya dapat dianggap sebagai objek yang merepresentasikan karakter bangsa yang membuatnya.

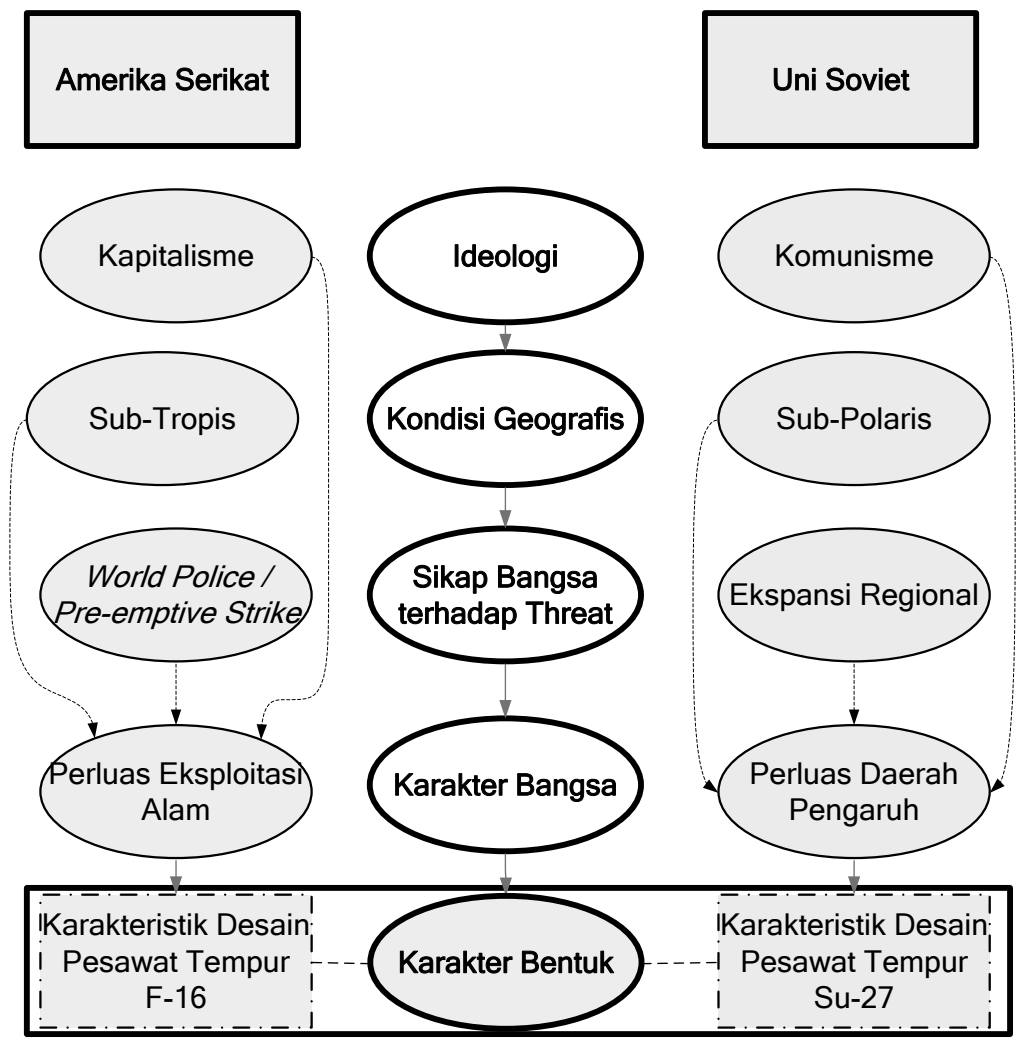

Gambar 1 Studi komparatif unsur karakter bangsa dan pengaruhnya terhadap penciptaan karya desain pesawat tempur. 
Gambar di atas menunjukkan bahwa hakikatnya karakter bangsa dibentuk oleh beberapa faktor utama seperti ideologi, kondisi geografis dan sikap bangsa tersebut menghadapi ancaman dari luar. Karya desain monumental, khususnya desain pesawat tempur dapat mewakili sikap budaya bangsa pembuatnya. Disamping kemajuan teknologi dan kebijakan politik, pesawat tempur F-16 lahir dari satu kebutuhan bangsa Amerika Serikat untuk terus menjaga wilayahnya, sedangkan pesawat tempur Su-27 lebih condong untuk digunakan sebagai alat deterrent atau menakut-nakuti lawan agar tidak berani mengganggu wilayah negara Rusia.

\section{$3 \quad$ Prinsip Desain dalam Komparasi Dua Objek}

Desain adalah usaha manusia untuk mendefinisikan, merancang dan menghasilkan benda atau alat yang berguna memudahkan kehidupan manusia yang semakin kompleks. [1] Di dalam karya desain terkandung pula prinsip totalitas yang dapat dipahami sebagai sebuah prinsip yang menekankan keterkaitan sebuah benda dengan karakter fungsi/serviceability dan estetik/appearance. [2] Desain memiliki banyak hal yang saling terkait satu sama lain, namun dengan prinsip totalitas ini kerumitan tadi dapat diamati secara lebih objektif.

Tabel 1 Pemetaan Karakteristik Desain Batu Potong melalui Prinsip Totalitas. (Sumber: Mayall, 1979)

\begin{tabular}{|c|c|c|c|}
\hline Features & $\begin{array}{l}\text { cutting } \\
\text { capacity }\end{array}$ & $\begin{array}{l}\text { handling } \\
\text { capacity }\end{array}$ & $\begin{array}{l}\text { aesthetic } \\
\text { appeal }\end{array}$ \\
\hline $\begin{array}{l}\text { Sharpness / ketajaman } \\
\text { Edge length / panjang bilah } \\
\text { Strength / kekuatan bilah } \\
\text { Mass / berat }\end{array}$ & $\begin{array}{l}\mathrm{O} \\
\mathrm{O} \\
\mathrm{O} \\
\mathrm{O}\end{array}$ & $\mathrm{o}$ & \\
\hline $\begin{array}{l}\text { Size / ukuran } \\
\text { Shape / bentuk } \\
\text { Texture / tekstur } \\
\text { Colour / warna } \\
\end{array}$ & & $\begin{array}{l}\mathrm{o} \\
\mathrm{o} \\
\mathrm{o}\end{array}$ & $\begin{array}{l}\mathrm{O} \\
\mathrm{O} \\
\mathrm{O} \\
\mathrm{O}\end{array}$ \\
\hline
\end{tabular}

Sebagai contoh sederhana adalah batu yang digunakan sebagai alat potong pada masa prasejarah. Batu pesegi itu adalah alat potong generasi pertama, prinsip totalitas pada benda ini sangat mudah ditentukan. Pertama-tama kutub karakter fungsionalitas yang menerangkan tugas utama dari benda ini ditentukan terlebih dahulu, yaitu fungsi daya potong. kemudian faktor estetik -yang menerangkan 
aspek paling non-teknis- di ujung yang satunya. Di antara kedua kutub ini direntangkan spektrum karakteristik yang dihasilkan benda kajian akibat interaksi benda ini dengan pengguna dan lingkungannya. Dari setiap karakteristik yang dihasilkan, akan dapat lihat elemen-elemen intrinsik apa saja yang berinteraksi dengan karakter eksternal benda tersebut. Sangat mungkin sebuah elemen intrinsik seperti massa akan mempengaruhi lebih dari satu karakteristik benda sekaligus.

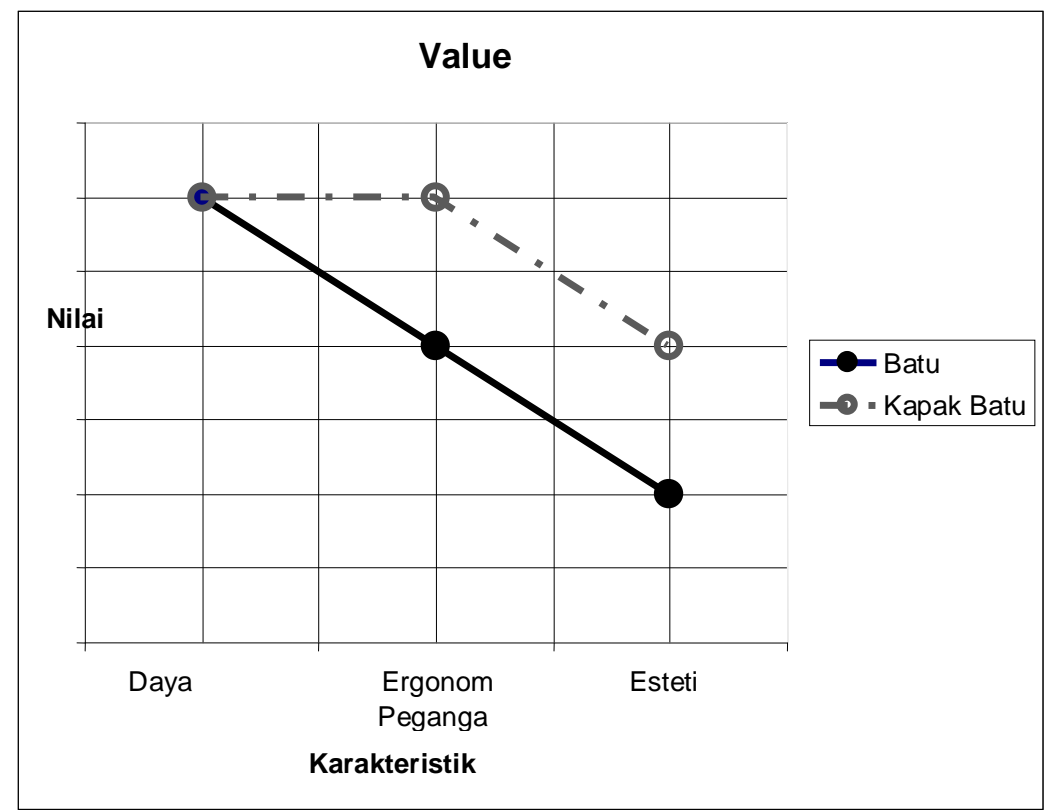

Gambar 2 Perbandingan Karakteristik Desain Batu Potong (Biru) dengan Kapak Batu (Merah) berdasarkan Prinsip Nilai. (Sumber : Mayall, 1979)

Demikian pula desain sebuah benda dapat dinilai kualitasnya menggunakan metoda Value Analysis [2]. Seperti halnya prinsip totalitas, memiliki dua kutub esensial yaitu nilai guna dan nilai kebanggaan. Nilai guna atau use value terkait dengan fungsi dasar sebuah benda. Sebuah kursi misalnya, telah memiliki nilai guna yang cukup apabila telah memiliki kemampuan untuk diduduki penggunanya. Nilai kebanggaan atau esteem value adalah sebuah nilai yang menunjukkan seberapa baik pengerjaan desainer atau produsen dalam membuat benda tersebut agar mampu mencapai fungsi dasarnya. Karakteristik sebuah produk dapat dihubungkan satu sama lain menggunakan nilai relatif yang memiliki tolak ukur kualitatif. Sebagai contoh batu potong yang telah dianalisa di atas dapat diurutkan semua karakteristik yang dimilikinya berdasar tingkatan nilai, jika cutting capacity diubah menjadi performance, handling quality menjadi ergonomics, maka karakteristik dari sebuah batu potong dapat 
dibandingkan dengan karakteristik sebuah kapak batu. Grafik di bawah menunjukkan bahwa batu potong dan kapak batu memiliki kesamaan prioritas dalam karakter performansi, ini berarti bahwa kedua peralatan ini memiliki nilai guna atau use value yang tinggi.

Sedangkan karakter lainnya jika diintegrasikan akan membentuk nilai kebanggaan. Cara mengukur nilai kebanggaan atau esteem value -atau aesthetic value pada kasus lain- cenderung bersifat kualitatif, sukar diukur secara kuantitatif tertentu namun lebih mudah dinilai oleh pengguna, karena nilai ini lebih banyak tercermin pada reaksi atau respon dari pengguna atau lingkungannya.

\section{Perbandingan Ideologi Amerika Serikat dan Rusia}

Pengertian peradaban yang digunakan adalah peradaban sebagai satuan sejarah, bukan sebagai perkembangan kebudayaan. Satuan sejarah seperti peradaban Mesir, Yunani dan Romawi, semua memiliki fondasi intelektual yang menjadi sumber inspirasi, patokan ide, dan sekaligus sebagai falsafah pemersatu bangsa. Fondasi yang sangat vital dan berakar ini adalah ajaran agama yang dianut secara resmi oleh negara. Homogenitas pemikiran menjadi 'harga mati' bagi pemerintah untuk mempertahankan kesatuan kekuasaan yang begitu luas. Ajaran agama ini dikodifikasi oleh para cendekiawan saat itu agar selaras dengan kondisi zaman dan mudah untuk dijadikan acuan dasar membentuk undang-undang dasar pemerintahan. Kodifikasi agama tersebut dikenal sebagai ideologi. Bagi peradaban yang kuat, keberadaan ideologi yang kuat sangat dibutuhkan agar peradaban tersebut mampu bertahan menghadapi berbagai badai peristiwa besar. Ideologi disebut kuat jika bersumber dari satu agama saja, yaitu agama yang resmi dianut pemerintah, sedangkan agama lain tetap diakui namun sebagai agama milik masyarakat. Sedangkan kekuatan ideologi sangat bergantung pada konsistensi masyarakat dan pemimpinnya menjalankan dan mentaati ajaran agama resmi tersebut.

\subsection{Peradaban berbasis Ideologi}

Toynbee menyatakan bahwa berpindahnya kekuasaan dari satu peradaban ke peradaban lain, selalu ditentukan oleh keberadaan senjata paling mutakhir [3]. Siapa yang memegang senjata paling mutakhir dapat diidentikkan dengan siapa yang memegang tongkat kendali kepemimpinan saat itu. Di masa sekarang masih menurut Toynbee- ada lima peradaban besar yang bertahan yaitu: Kristen Barat (Protestan, Katolik), Kristen Timur (Ortodok), Hindu, Budha dan Islam. Semua peradaban -kecuali Islam- berlomba untuk mampu mengendalikan dunia, atau paling tidak bertahan mati-matian agar tidak menjadi peradaban yang paling lemah yang hanya menjadi bulan-bulanan sebagai pasar dari produk 
konsumtif negara lain. Salah satu indikatornya adalah keinginan untuk menguasai ilmu produksi senjata paling mutakhir. Pesawat tempur adalah salah satu bentuk senjata yang paling mutakhir itu. Pada era Perang Dingin, peradaban Barat yang diwakili oleh ideologi Kapitalisme dan peradaban Timur yang diwakili oleh ideologi Komunisme secara agresif mengembangkan pesawat tempur paling canggih dan mutakhir sebagai simbolisasi prestise kedigjayaan negara adikuasa dengan ideologinya.

\section{$5 \quad$ Teori Karakter Bangsa [4]}

Pemikiran Richard Lewis seorang manajer pemilik perusahaan manajemen berskala internasional dengan kantor cabang tersebar di 30 negara menunjukkan bahwa dalam memimpin karyawan yang multi etnis dan multi kultur ditulis dalam buku "When Culture Collide: Managing Successfully Across Cultures". Buku ini membahas generalisasi kasus-kasus yang sifatnya personal menjadi sebuah model untuk melihat karakter bangsa. Cara ini memang tidak ideal namun dengan menggunakan beberapa asumsi dan beberapa pembatasan kasus, kisah-kisah yang dipaparkannya bisa menjadi petunjuk praktis untuk melihat cara berpikir sebuah bangsa. Secara umum, Lewis membagi karakter bangsa-



Gambar 3 Posisi karakter budaya bangsa Amerika dan Rusia dalam Cultural Type menurut Lewis - (Sumber: "When Culture Collide”, Richard Lewis) [5]. 
bangsa di dunia menjadi tiga jenis yaitu : aktif-linear, reaktif, dan multi-aktif. Jika diamati gambar 'Lewis' di bawah, Amerika Serikat dan Uni Soviet (Rusia) terletak dalam satu garis yang menghubungkan multi-aktif dengan linear-aktif, hal ini menunjukkan bahwa adanya kemiripan dari kedua bangsa, yaitu samasama Kaukasoid. Namun keduanya menjadi berbeda karena faktor ideologi yang berlainan.

\section{Ciri Ideologis pada Simbol Negara}

Terbitnya buku „An Inquiry Into the Nature and Causes of the Wealth of Nations" atau yang terkenal dengan "Wealth of Nations" karangan Adam Smith bersamaan waktunya dengan kemerdekaan negara Amerika Serikat yang berlandaskan pada liberalisme. Begitu juga buku "Communist Manifesto" karya Lenin menjadi inspirasi utama negara Uni Sovyet yang kemudian menjadi ciri ideologis negera itu.

- Elang Romawi $\rightarrow$ lambang agresifitas

- Daun $\rightarrow$ perdamaian

- Panah $\rightarrow$ perang

- Perisai $\rightarrow$ perlindungan

- Banyak bintang $\rightarrow$ desentralisasi kekuasaan

- Cahaya multi bintang $\rightarrow$ demokrasi menjadi inspirasi bangsa

- "God favors our undertaking" $\rightarrow$ mencap diri sebagai bangsa yang dipilih Tuhan (narsisisme)

Gambar 4 Lambang Negara Amerika Serikat. (sumber:

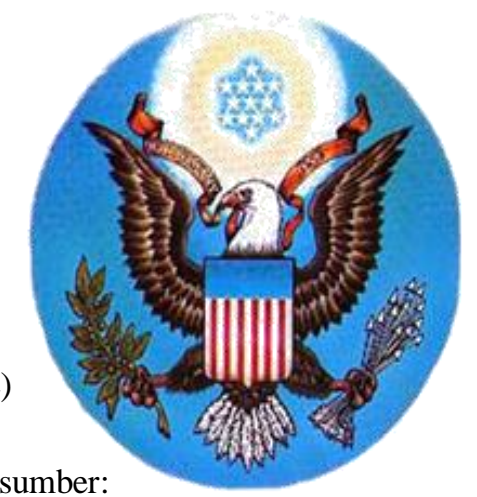
en.wikipedia.org/wiki/Great_Seal_of_the_United_States, 29 Juli 2007)

- Kapak arit $\rightarrow$ petani dan buruh sebagai kelas yang dibela

- Dunia $\rightarrow$ dominasi global

- Padi $\rightarrow$ orientasi kemakmuran di bidang pertanian

- 1 Bintang $\rightarrow$ kekuasaan terpusat

- Sinar Matahari bercahaya $\rightarrow$ alam menjadi inspirasi bangsa

- $\quad$ "Workers of All Countries, Unite!" $\rightarrow$ menekankan solidaritas bangsa sebagai kekuatan negara

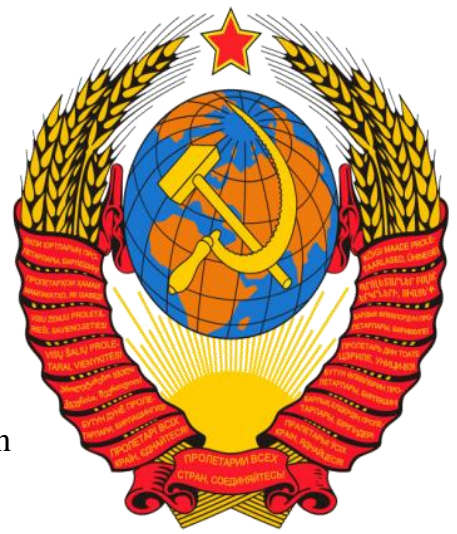

Gambar 5 Lambang Negara Uni Soviet. (sumber: en.wikipedia.org/wiki/Coat_of_arms_of_the_Soviet_Union, 29 Juli 2007) 
Falsafah hidup di kedua negara di atas dapat dikatakan sebagai bentuk implementasi kedua ideologi yang yang berbeda. Simbol dan emblem yang digunakan kedua negara dapat menjadi ciri mengenai bagaimana prinsip kedua ideologi diimplementasikan falsafah hidup dan dalam kehidupan sehari-hari.

\section{$7 \quad$ Ciri Ideologis pada Produk Negara}

Di era Perang Dingin, kedua negara adidaya di atas berlomba memenangkan 'Space Race'. Negara yang diunggulkan adalah Amerika Serikat yang mampu menginjakkan kaki manusia di bulan pertama kali, namun karena menggunakan pola pendekatan engineering yang berbeda, roket buatan Rusia dapat bertahan hingga kini. Bahkan dengan berakhirnya era 'Space Shuttle', roket Rusia menjadi satu-satunya jembatan penghubung bagi manusia di bumi dengan ISS (International Space Station). Perbedaan pendekatan ini lahir dari konsep worldview yang sangat bertolak belakang dari ideologi masing-masing negara.

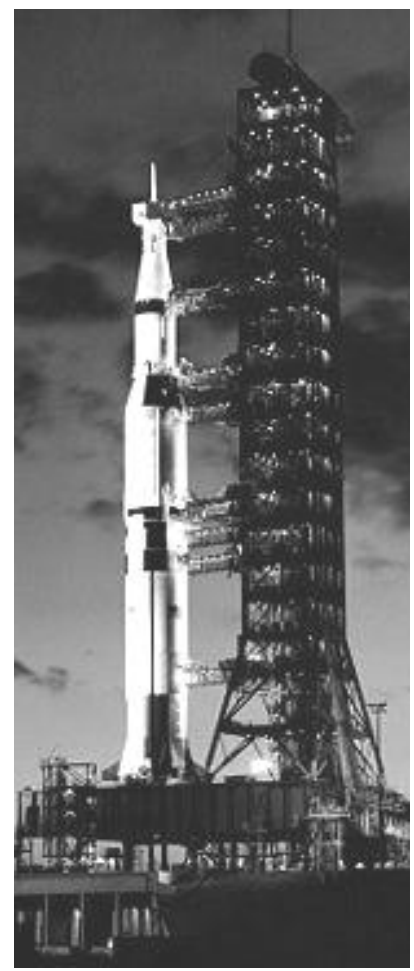

- Antar-stage berbentuk cone menunjang penciutan ukuran radius silinder secara bertahap dan menjadikan roket paling bawah berperan sebagai pendorong internal

- Roket stage 1 memiliki 5 nozzle berukuran raksasa

- Penyusunan stage secara vertikal

- Perancang : Wernher von Braun memiliki reputasi sebagai ilmuwan yang populer dan dihormati

- Dirancang sebagai wahana eksplorasi ruang angkasa

- menekankan terobosan-terobosan inovasi yang sangat menguras biaya dan sumber daya alam

- $\quad$ saat ini roket tidak diproduksi lagi

Gambar 6 Roket Saturn V. (sumber: en.wikipedia.org/wiki/Saturn_V, 23Nov 2007) 




- Strap-on booster membentuk piramida penyangga yg berperan sebagai pelontar eksternal bagi roket utama

- Roket stage 1 memiliki 20 nozzle yang berukuran sedang dan seragam dengan nozzle pada stage 2 dan 3

- Penyusunan stage secara horisontal

- Perancang : identitas Korolyov sangat dirahasiakan dan selalu bekerja di bawah pressure

- Mengadopsi rancangan rudal balistik jarak jauh (R-7)

- mengutamakan penyempurnaan gradual hingga mencapai fungsionalitas optimal dan biaya minimum

- masih diproduksi hingga kini

Gambar 7 Roket Soyuz. (sumber: en.wikipedia. org/wiki/Soyuz, 23 Nov 2007)

\section{$8 \quad$ Karakteristik Desain Pesawat Tempur}

\subsection{Karekteristik Performansi}

Tingkat probabilitas kesuksesan sebuah pesawat tempur menjalankan misinya bergantung pada 8 karakteristik desain pesawat [6], yaitu:

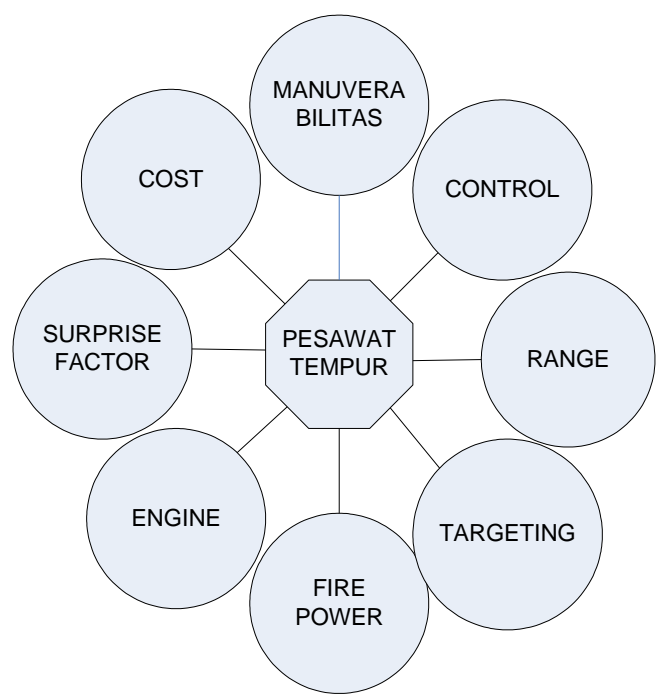

Gambar 8 Diagram 8 karakteristik desain pesawat tempur versi Huenecke, 1987. 


\subsection{Jenis Pesawat Tempur berdasarkan Misi}

Misi pertempuran merupakan pijakan dasar dari desain pesawat tempur. Perbedaan misi akan membawa konsekuensi keteknikan yang berbeda, seperti aerodinamika, propulsi, persenjataan, avionik dan seterusnya. Sebuah pesawat yang mampu menjalankan semua misi disebut pesawat multi-role, tetapi efektifitas pencapaian misi yang rendah.

Misi pertempuran terbagi dua jenis, yaitu serangan udara dan serangan darat. Untuk misi serangan udara terbagi atas:

1. Air-to-Air Mission

- Air Superiority Fighter atau Petarung Keunggulan di Udara

Di antara semua jenis misi pertempuran, misi air superiority adalah yang paling tinggi nilainya. Tugas utama pesawat air superiority adalah meraih supremasi udara. Ciri misi Air Superiority menentukan desain pesawat air superiority. Hal yang menentukan kesuksesan terbang bukanlah kecepatan tertinggi, tapi kemampuan untuk melakukan dogfight atau pertempuran jarak dekat dengan manuver sambil menahan pelipatan beban gaya gravitasi yang tinggi. Manuverability ditentukan oleh : prestasi daya tanjak, kapasitas akselerasi dan kecepatan belok.

- Interceptor atau Penyergap

Tugas pesawat interceptor adalah menyergap yang berlangsung di dalam areal kerja pertahanan udara negara sendiri, sebagai reaksi jika ada lawan yang menyerbu atau menyelusup masuk ke wilayah tersebut. Pesawat lawan ini dideteksi masuk oleh radar terbang atau radar di darat.

2. Air-to-Ground Mission

- Close air support atau Bantuan Serang Darat

Misi bantuan udara jarak dekat atau close air support, berperan sebagai perpanjangan tangan dari pasukan angkatan darat yang menyerbu ke daerah lawan. Tugas utamanya adalah menghancurkan sasaran yang berada di garis depan medan pertempuran, kurang lebih $40 \mathrm{~km}$ dari garis batas tengah pertempuran. 


\section{- Interdiction atau Penyekatan}

Interdiction atau penyekatan adalah sebuah misi yang menjadikan areal di belakang garis tempur lawan sebagai sasaran. Tujuannya adalah memotong jalur logistik, menghancurkan cadangan suplai BBM, agar mengentikan kebebasan gerak pasukan lawan yang ada di garis depan. Misi ini harus dijalankan dalam segala cuaca, baik siang maupun malam. Areal target terletak di antara jarak $40 \mathrm{~km}$ hingga $100 \mathrm{~km}$ di belakang garis pertempuran.

\subsection{Desain Pesawat Tempur [7]}

Sebuah pesawat tempur yang dalam proses perancangan, umumnya memiliki karakteristik yang lebih tinggi daripada pesawat yang saat itu berada di pasaran. Kebutuhan untuk mengganti perlengkapan yang sudah ketinggalan jaman menumbuhkan pemikiran baru pada staf pertahanan dan industri penerbangan mengenai bagaimana pesawat tempur baru itu harus dirancang. Beberapa pertimbangan tersebut:

a. penggunaan teknologi paling mutakhir

b. memenuhi misi yang ditetapkan pihak militer

c. dapat dimiliki oleh angkatan udara dalam jumlah yang banyak (berarti biaya murah)

Adanya kebutuhan itu kemudian melahirkan "konsep desain" baru. Konsep desain pesawat tempur berarti merepresentasikan sebuah periode waktu yang berkaitan dengan kriteria masa depan dari pesawat tempur itu ditentukan, dan juga keputusan jenis teknologi yang akan digunakan. Semakin dalam dan berpandangan jauh ke depan dalam merumuskan konsep desain pesawat tempur, semakin tinggi harapan pesawat tempur memberikan keunggulan strategis.

\section{$9 \quad$ Perbandingan Bentuk Estetik}

Salah satu cara untuk melihat perbedaan konsep desain di antara kedua pesawat tempur ini adalah dengan mempelajari nickname atau penjulukan yang diberikan desainer penciptanya. Penamaan ini bukan menceritakan datangnya inspirasi atau makhluk yang menjadi sumber ide bagi sang desainer dalam menciptakan pesawat, namun bagaimana sang desainer memberi jati diri pada karya ciptaannya. Nama binatang yang diambil menjadi sebuah metafora yang melambangkan sifat-sifat keunggulan yang dimiliki binatang tersebut dapat tercermin pada pesawat tempur ciptaannya. 


\subsection{Bentuk Tampak Samping}



Gambar 9 Burung Prairie Falcon (http://www.birdsofprey.blm.gov/img/ falcon10.jpg-04agus 07)



Gambar 11 F-16 dijuluki "Fighting Falcon" - (www.f16.net-14jan07)

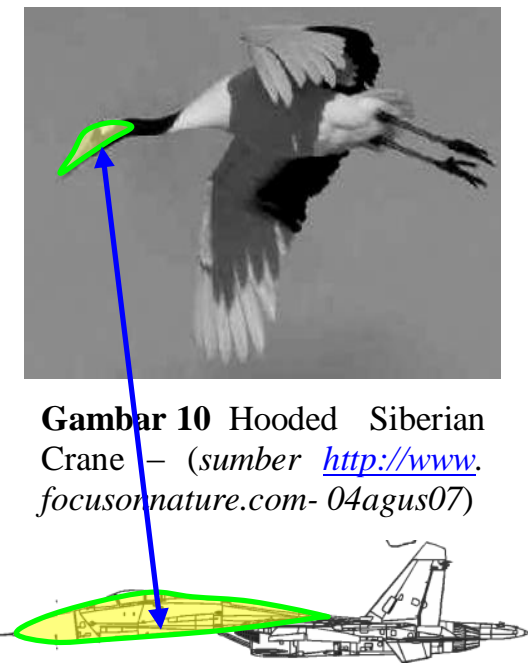
Gambar 12 Su-27
yang dinamakan Siberian Crane - (sumber : afbase.com-14apr07)

Tabel 2 Perbandingan Metafora Bentuk tampak samping.

\begin{tabular}{l|l}
\hline Amerika Serikat menamakan secara resmi & Su-27 di mata masyarakat Rusia \\
pesawat F-16 sebagai Fighting Falcon. & dijuluki sebagai "Siberian crane" atau \\
Falcon adalah semacam elang, sebuah & bangau Siberia, burung kebanggaan \\
burung predator yang memiliki kepala besar & Rusia yang populasinya sudah merosot \\
dengan mata bersorot tajam, berleher pendek & tajam dan terancam punah. \\
dengan paruh lancip berujung bengkok. Di & Burung ini memiliki leher panjang dan \\
bawah leher, dadanya membusung & tertekuk seperti angsa, paruh yang \\
menampakkan kekokohan dan kegagahan. & panjang, kaki yang panjang, dan badan \\
Kegagahan burung predator sangatlah & yang sedikit oval seperti badan ayam, \\
fenomenal, sehingga banyak negar dan & sepintas menampakkan kemiripan \\
institusi yang menggunakan burung falcon & dengan flamingo, bangau berwarna \\
sebagai lambang maupun emblem. & pink. Struktur tubuh yang dominan \\
Jika dilihat dari samping, bentuk badan & panjang menunjukkan bahwa burung \\
burung falcon tampak streamline atau & ini memiliki ciri yang tidak \\
sempurna secara aerodinamis sehingga & menonjolkan agresifitas, cenderung \\
sangat membantu burung in dalam & lembut, anggun, dan tidak rakus dalam \\
menyambar mangsa dengan kecepatan & mencari mangsa.
\end{tabular}
tinggi. Jadi, burung falcon ini pun melambangkan kegesitan dan kelincahan. 


\subsection{Bentuk Tampak Depan}

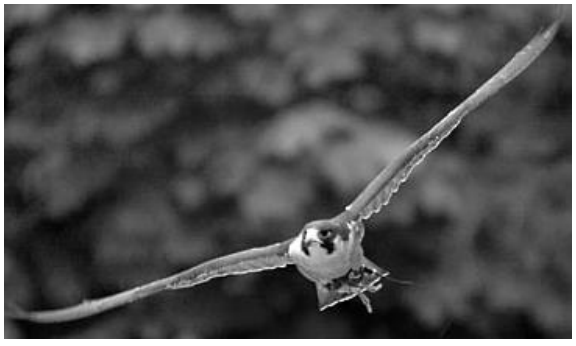

Gambar 13 Burung Falcon dilihat dari depan.- (www.aviary.org04agus07)

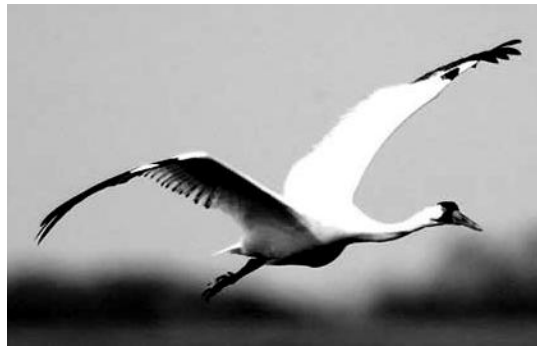

Gambar 14 Burung Siberian Crane terbang dilihat dari samping agak depan tampak memiliki tubuh yang memanjang- sumber (http://www.photobirder.com/Bird _Photos/sandhill_crane_fly.jpg04agus07)

Tabel 3 Perbandingan metafora bentuk burung tampak depan.

Burung falcon jika tampak dari depan,
terlihat memiliki badan yang pipih,
melebar ke samping. Sayap terbentang
lebar, digunakan terutama untuk melayang
dengan kecepatan rendah, mengelilingi
daerah mangsa. Sirip belakang mengarah
ke bawah untuk melakukan pengereman
dan pengarahan sudut terbang.
Kesan yang didapat jika melihat burung
falcon dari depan sangat menonjolkan
kegagahan dan keberanian dalam
melakukan penyergapan terhadap mangsa
yang lebih kuat dan besar sekalipun. Nilai
informasi tambahan dari pose burung
falcon seperti tampak pada foto di atas
menunjukkan bahwa burung tersebut
memiliki kemampuan untuk mengubah
energi potensial (ketinggian) menjadi
energi kinetik (kecepatan) dalam waktu
singkat.

Burung bangau siberia ini memiliki badan yang panjang dan didominasi oleh lehernya, memiliki bentangan sayap yang lebar diperkuat oleh kaki yang lurus memanjang dan menjulur ke arah belakang. Gaya terbang burung ini menekankan pada kestabilan terbang lurus daripada kelincahan manuver. Hal ini dikarenakan:

- makanannya lebih banyak berupa biji-bijian (herbivora) daripada binatang (karnivora).

- Jam terbangnya dihabiskan oleh proses migrasi antar wilayah daripada mencari makanan 




Gambar 15 F-16 tampak dari depan - (www.f16.net-14apr07)

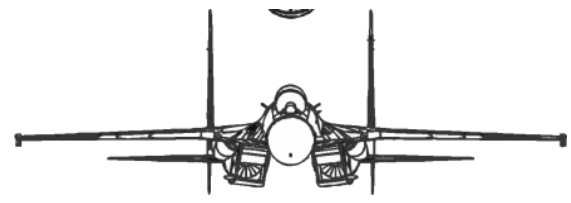

Gambar 16 Bentuk geometri pesawat Su-27 tampak depan (afbase.com-14apr07)

Tabel 4 Perbandingan bentuk pesawat tempur dari depan

\begin{tabular}{l|l}
\hline Pesawat F-16 jika dilihat dari depan & $\begin{array}{l}\text { Pesawat Su-27 memiliki analogi bentuk } \\
\text { memiliki kemiripan dengan burung falcon } \\
\text { yang mirip dengan karakter bangau }\end{array}$ \\
yaitu ukuran badan yang kecil namun & $\begin{array}{l}\text { Siberia, yaitu harus mampu terbang jauh } \\
\text { pipih melebar ke samping. Kemampuan } \\
\text { dengan sedikit frekuensi untuk mengisi }\end{array}$ \\
mengubah energi ketinggian menjadi & $\begin{array}{l}\text { bahan bakar. Pesawat ini memiliki } \\
\text { energi kecepatan terlihat dari ukuran }\end{array}$ \\
kestabilan yang baik, sehingga kebutuhan \\
mesin yang lebih dominan dibandingkan \\
akan komputer tidak setinggi pesawat F- \\
$\begin{array}{l}\text { dengan keseluruhan bentuk badan } \\
\text { pesawat. }\end{array}$
\end{tabular}

\subsection{Bentuk Fuselage (Badan Pesawat)}

Badan pesawat atau fuselage adalah bagian utama dari pesawat, di dalamnya tersimpan sebagian besar peralatan vital, seperti bahan bakar, komputer, sistem hidrolik, sistem listrik, kokpit, radar, roda, kerangka dan mesin.

Tabel 5 Perbandingan bentuk dasar fuselage.

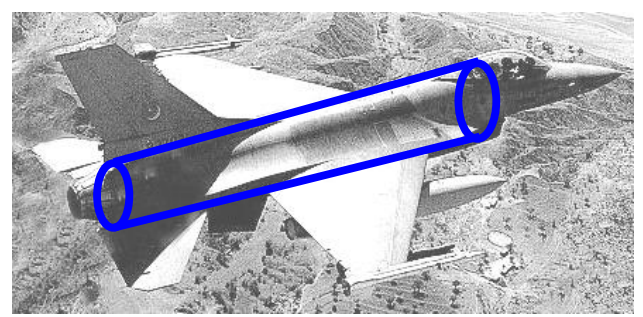

Gambar 17 Bentuk dasar fuselage F-16: Silinder-

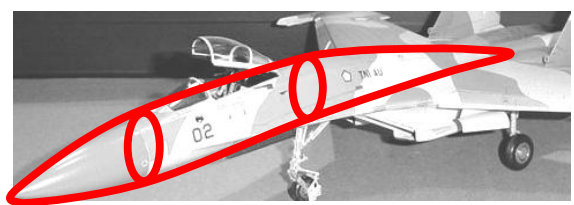

Gambar 18 Bentuk dasar fuselage Su-27: Punuk-. 


\subsection{Radome}

Radome F-16 memiliki penampang berbentuk oval atau elips, sedangkan Su-27 berbentuk penampang lingkaran sempurna.

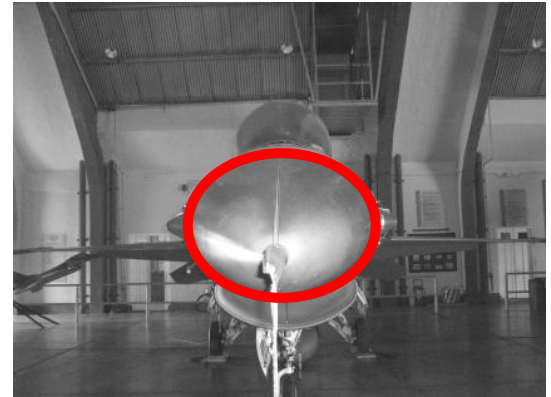

Gambar 19 Penampang radome F-16 berbentuk elips atau oval.

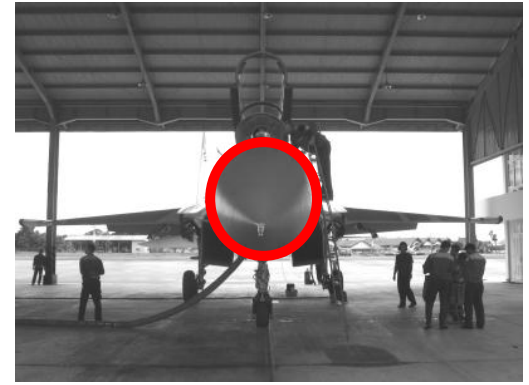

Gambar 20 Penampang radome Su-27 berbentuk lingkaran sempurna

Tabel 6 Perbandingan Bentuk Penampang Radome Pesawat F-16 dan Su-27.

$\begin{array}{ll}\text { Pada F-16, ukuran bentuk } & \text { Pada Su-27, drag parasite tidak terlalu } \\ \text { penampang pesawat ditentukan } & \text { dipermasalahkan karena perancang } \\ \text { berdasarkan penampang yang } & \text { Sukhoi memang hendak memasukkan } \\ \text { menghasilkan gaya hambat sekecil- } & \text { radar yang besar, kuat dan berdaya } \\ \text { kecilnya (drag parasite) agar bahan } & \text { jangkau jauh yaitu NIIP N011M BARS } \\ \text { bakar tidak terbuang percuma } & \text { (daya jejak hingga } 160 \mathrm{~km} \text { ) }\end{array}$

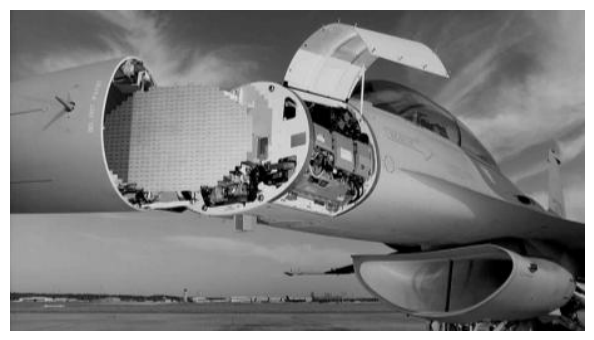

Gambar 21 Pada F-16, Antena Radar Westinghouse AN/APG66. (sumber: www.westinghouse. com-17des06)



Gambar 22 Pada Su-27, Antena Radar NIIP N011M BARS (sumber: $\quad$ www.ausairpower.net19jan07). 
- piringan antena berbentuk oval dan kecil

- peralatan radar yang dibawa F16 adalah radar berkemampuan menjejak dalam jarak dekat hingga menengah $(\max 150 \mathrm{~km})$ AN/APG-66 yang berbobot sekitar $100 \mathrm{~kg}$.

- menekankan pelacakan visual jarak dekat
- piringan antena berukuran besar dan bulat

- peralatan radar berkemampuan menjejak dan mengunci 10 lawan sekaligus dalam jarak maximum $166 \mathrm{~km}$.

- menekankan pada pelacakan radar jarak jauh

\subsection{Kanopi}

Salah satu faktor bentuk yang berperan penting dalam pertempuran di udara adalah bentuk kanopi. Bentuk kanopi ini sangat berpengaruh pada pandangan pilot, bentuk yang ideal adalah kanopi yang tidak menghalangi pandangan pilot.

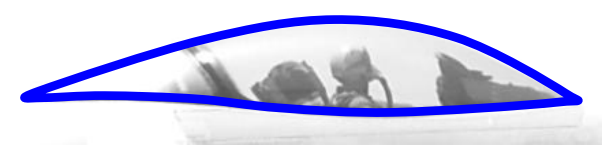

Gambar 23 Kanopi F-16.



Gambar 24 Kanopi Su-27.

Tabel 7 Tabel perbandingan bentuk kanopi.

\begin{tabular}{ll}
\hline Kanopi F-16 lebih mendekati tuntutan & Keberadaan struktur penyangga kaca \\
ideal meskipun masih ada penyangga tapi & Pada kanopi Su-27 cukup mengganggu \\
hanya di bagian belakang saja. & Keberadaan penyangga kaca pada Su-27 \\
Kelemahan kanopi F-16 adalah sinar & ternyata selain untuk menyangga juga \\
matahari kurang terhalangi, sehingga & berperan dalam mengalirkan panas dalam \\
menimbulkan 'efek rumah kaca' bagi pilot & kokpit ke seluruh tubuh, sehingga AC \\
yang ada di dalamnya. Hal itu dipecahkan & kurang diperlukan. \\
melalui pemberian cat pelapis yang & Di samping itu, pada penyangga terdapat \\
meredupkan efek inframerah matahari dan & kaca spion yang membantu pilot untuk \\
penambahan AC di dalam kokpit F-16 & $\begin{array}{l}\text { melihat bagian belakang, seperti layaknya } \\
\text { spion mobil. }\end{array}$
\end{tabular}




\subsection{Sayap}

Sayap bagi sebuah pesawat adalah unsur yang penting. Gaya-gaya aerodinamika yang memiliki fungsi untuk mengangkat seluruh beban pesawat berasal dari permukaan sayap ini.

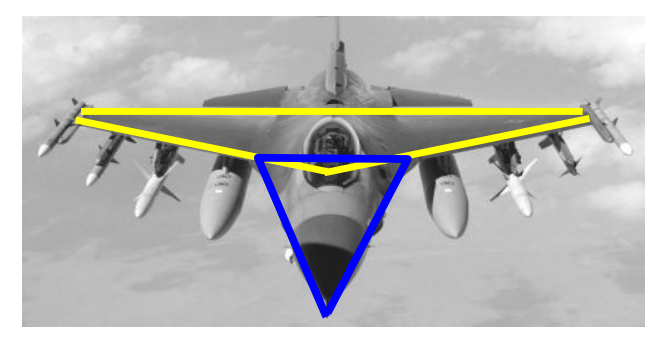

Gambar 25 Bentuk sayap pesawat F16 (sumber: www.f16.net-14Apr07)



Gambar 26 Bentuk sayap pesawat Su-27 (sumber: afbase.com-14 Apr07)

Tabel 8 Perbandingan Siluet Sayap.

Dilihat dari depan atas, tampak memiliki bentuk yang khas yaitu sayap utama miring ke belakang, dan pada bagian tengah terdapat tambahan permukaan sayap berbentuk segitiga
Dilihat dari depan , sayap Su-27, tampak mirip dengan F-16 hanya bagian tengah agak menyudut.

\section{Rangkuman Faktor-faktor Aspek Tangible dan Aspek Intangible}

Tabel 9 Aspek Tangible (Karakter Bentuk)

\begin{tabular}{ccc}
\hline $\begin{array}{c}\text { Aspek Tangible } \\
\text { Bentuk }\end{array}$ & F-16 & Su-27 \\
\hline Radome & Jangkauan pendek & Jangkauan jauh \\
Kanopi & Orientasi kenyamanan pilot & Fungsional misi tempur \\
Sayap & Kecil + Temuan penting & Besar + LEX Tiruan \\
Rel rudal & LEX & Gjektor \\
Struktur & Beban terdistribusi & Terpusat \\
Fuselage & Silindris $\rightarrow$ robotik/artifisial & Punuk $\rightarrow$ bionik/naturalis \\
Kualitas finishing & Halus & Kasar \\
\hline Rem & Efisien & Efektif
\end{tabular}




\begin{tabular}{ccc}
\hline $\begin{array}{c}\text { Aspek Tangible } \\
\text { Bentuk }\end{array}$ & F-16 & Su-27 \\
\hline Air intake & Sederhana & Rumit \\
Roda & Rumit & Sederhana \\
Ekor & Pod - mekanistik & Ekor berang-berang - \\
bionik \\
Identifikasi & Ukuran kecil susah dilacak & 2 air intake sangat kentara \\
\hline
\end{tabular}

Tabel 10 Aspek Intangible (Ideologi dan Karakter Bangsa)

\begin{tabular}{|c|c|c|}
\hline Aspek Intangible & F-16 & Su-27 \\
\hline Aspek Ideologi & Kapitalisme & Komunisme \\
\hline $\begin{array}{c}\text { Kebijakan Politik Luar } \\
\text { Negeri }\end{array}$ & World Police & Ekspansi Pengaruh \\
\hline Pendekatan Militer & Agresif - Konfrontatif & Defensif - Deterrent \\
\hline Pola Kepemiminan & Distribusi Kekuasaan & Terpusat \\
\hline Gaya Kepemimpinan & Demokratis & Otoriter \\
\hline Hubungan Kerja & Egaliter & Hirarkis \\
\hline $\begin{array}{c}\text { Manajemen Sumber } \\
\text { Daya }\end{array}$ & $\begin{array}{c}\text { Boros - Manipulatif- } \\
\text { Royal - } \\
\text { Eksploitatif }\end{array}$ & $\begin{array}{c}\text { Hemat - Alamiah - Seperlunya } \\
\text { - Konservasi }\end{array}$ \\
\hline Pendekatan Pola Hidup & $\begin{array}{c}\text { artifisial / robotik / } \\
\text { otomatik }\end{array}$ & Naturalis - bionik - manual \\
\hline Corak Masyarakat & Individualis & Sosial \\
\hline Keinginan Berprestasi & Inisiatif/Antusiastik & Menunggu/Reaksioner \\
\hline Inspirasi Sumber Ide & Kreativitas / Orisinalitas & Historis / Tradisional \\
\hline Pola Ekspresi & $\begin{array}{l}\text { Liberalis / } \\
\text { Free Will }\end{array}$ & Keteraturan / Pietis \\
\hline Beauty Criteria & $\begin{array}{c}\text { Materialistik (Outer } \\
\text { Beauty) }\end{array}$ & Spiritualistik (Inner Beauty) \\
\hline
\end{tabular}

\subsection{Karakter Bentuk}

Analisa prinsip totalitas dan prinsip nilai digabung dalam satu kombinasi grafik bertumpuk dalam bentuk satu kuadran. Dalam kuadran ini ditentukan terlebih dahulu daerah 'normal' yang merepresentasikan kesesuaian antara aspek tangible (yang diwakili oleh karakteristik bentuk) dengan aspek intangible (yang diwakili oleh karakter bangsa dan ideologi). 


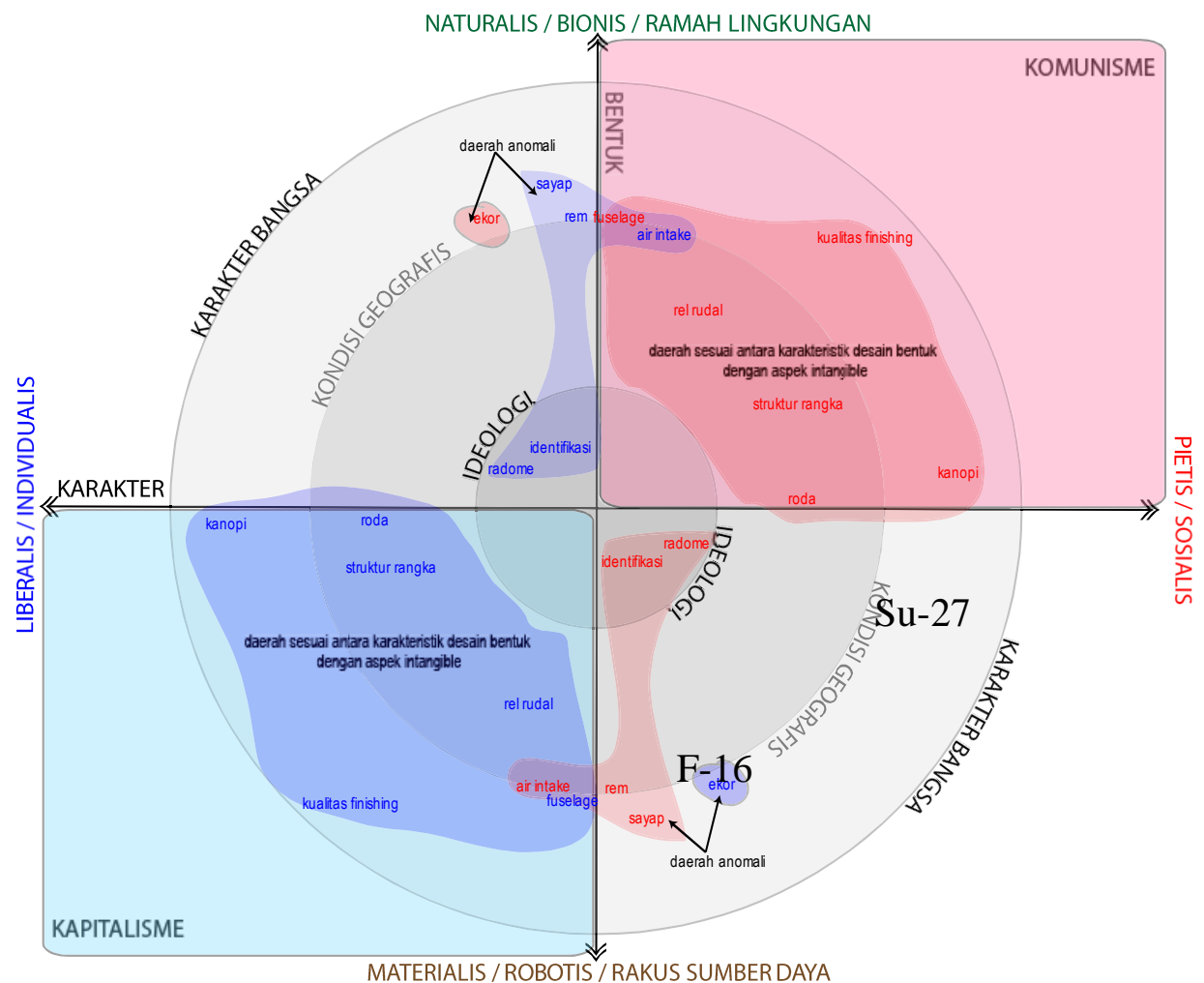

KUADRAN KARAKTER BENTUK

Gambar 27 Kuadran Karakter Bentuk, Implementasi Ideologi pada desain bentuk F-16 dan Su-27.

Konsep kuadran karakter bentuk peinsipnya tidaklah jauh dari prinsip totalitas desain dan prinsip nilai yang disampaikan oleh Mayall. Kuadran ini digunakan untuk melihat pengaruh aspek intangible (ideologi dan karakter bangsa) pada aspek tangible (karakteristik desain bentuk). Dengan memperhatikan kesalahan peletakan komponen benda pada kuadran karakter bentuk, digunakan daerah kemungkinan peletakan. Penggunaan daerah peletakan ini justru bisa memandu untuk melihat sejauh mana konsistensi bangsa pencipta benda terpengaruh oleh ideologi dalam berkarya. 


\subsection{Perbandingan Faktor Tangible pada 5 Karakteristik Desain lain secara prinsip Nilai (Value Analysis)}

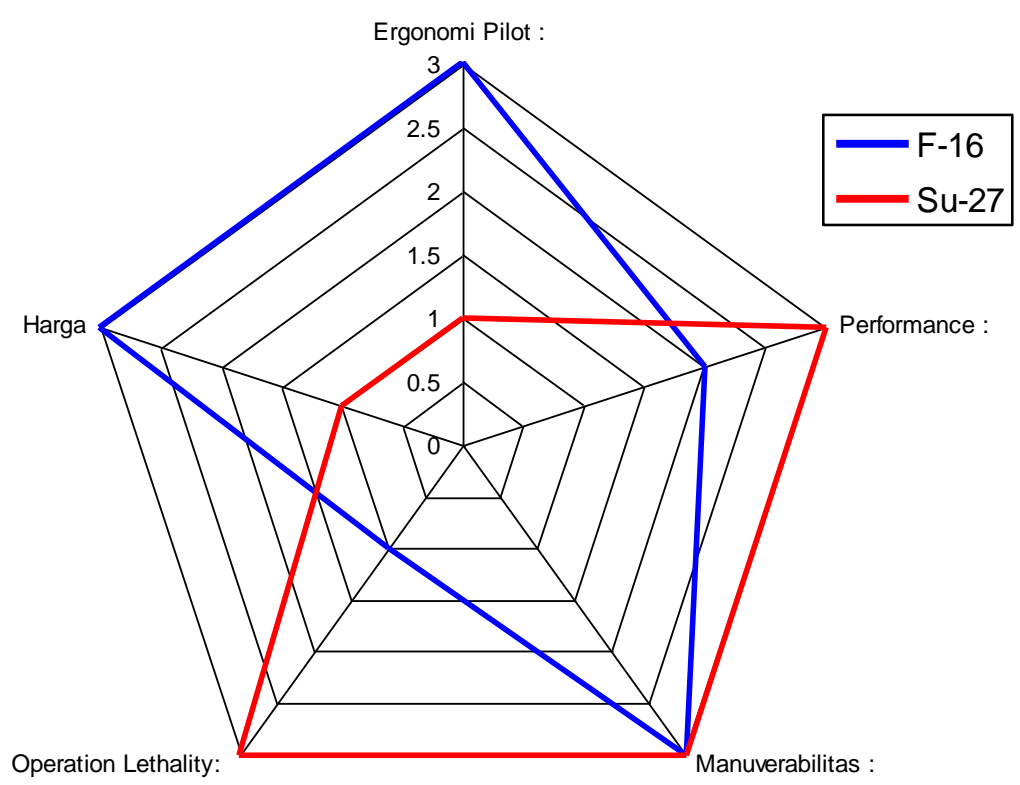

Gambar 28 Diagram Analisis Nilai terhadap Aspek Tangible (5 Karakteristik Desain lain)

Pada gambar 31, terlihat bahwa kemampuan kedua pesawat ini saling mengisi. Kelebihan dan kekurangan kedua pesawat cenderung bertolak belakang pada setiap karakteristik desain, kecuali pada manuverabilitas bahwa kedua pesawat menempati angka tertinggi, hal ini menunjukkan kedua pihak menempuh pendekatan dan memiliki filosofi yang berbeda untuk meraih tujuan yang sama, yaitu meraih air superiority atau keunggulan di udara.

Tabel 11 Perbandingan perbedaan pendekatan manajemen sumber daya

\begin{tabular}{|c|c|}
\hline $\begin{array}{l}\text { Amerika Serikat, meskipun versifat } \\
\text { anomali, namun mampu menciptakan } \\
\text { pesawat tempur berbiaya "sangat murah", } \\
\text { dan hasil sampingan risetnya pesawat } \\
\text { digunakan untuk keperluan sipil. }\end{array}$ & $\begin{array}{l}\text { Pihak Uni Soviet yang } \text { selalu } \\
\text { menggembar-gomborkan hidup sederhana } \\
\text { pada kaum proletarnya, ternyata } \\
\text { bersikap"sangat boros“ jika menyangkut } \\
\text { keperluan militernya. }\end{array}$ \\
\hline $\begin{array}{l}\text { Dampaknya, para ilmuwan di pihak } \\
\text { kapitalis akan selalu bersemangat } \\
\text { berkarya pada bidang apapun, untuk } \\
\text { keperluan siapapun, apakah militer } \\
\text { ataupun sipil, sehingga melahirkan } \\
\text { sebuah karakter bangsa : spesialisasi. }\end{array}$ & $\begin{array}{l}\text { Dampaknya para ilmuwan di pihak } \\
\text { komunis akan bersemangat jika berkarya } \\
\text { untuk keperluan militer, sedangkan dunia } \\
\text { sipil hanya mengikuti perkembangan dunia } \\
\text { militer, hasilnya adalah karakter bangsa : } \\
\text { generalisasi. }\end{array}$ \\
\hline
\end{tabular}




\section{Simpulan}

Karakter bangsa bernilai positif dapat tercermin pada bentuk estetik pesawat tempur. Ukuran pesawat tempur F-16 yang kecil menunjukkan bahwa desainer Amerika Serikat cenderung spesialis karena ukuran kecil ini menyebabkan pesawat F-16 memang difokuskan tugasnya untuk bertempur, sedangkan ukuran Su-27 yang besar menghasilkan kemampuan multi-tasking (mulai dari bertempur, hingga menyergap) dan ini menjadi petunjuk bahwa desainer Uni Soviet cenderung generalis. Hal tersebut diperkuat oleh kenyataan terkini yang menyatakan Angkatan Udara Rusia tidak mengembangkan pesawat tempur ringan (LFI) untuk beberapa waktu ke depan, tapi fokus pada pesawat tempur menengah (MFI) yang berkemampuan serba bisa.

Dari karakter bentuk dari kedua pesawat tempur di atas, dapatlah diambil intisari dari watak asli atau karakter bangsa Amerika Serikat dan Uni Soviet dalam mengekspresikan karya desain yaitu:

1. Amerika Serikat $\rightarrow$ spesialis

- Spesialis berarti kemampuan diri difokuskan ke salah satu tugas mendasar dan kurang fokus pada tugas lain.

- Keuntungan dari cara ini adalah kesempurnaan produk.

2. Uni Soviet $\rightarrow$ generalis

- Generalis berarti kemampuan diri disebar pada beberapa tugas.

- Keuntungan dari cara ini adalah kuantitas produksi dan biaya yang murah.

\section{Referensi}

[1] Sachari, Agus, et al., 1999, Modernisme, sebuah tinjauan historis desain modern. Balai Pustaka, Jakarta.

[2] Mayall, W.H., 1979, Principles in Design. Design Council, London, h 67.

[3] Marshall McLuhan, 1967, Understanding Media, Sphere Publishing, London.

[4] Hacker, Barton C., The Machines of War: Western Military Technology 1850-2000, History and Technology, Vol. 21, No. 3, September 2005, h 255-300; h 255.

[5] Gambar yang dikemukakan oleh Lewis, Richad dalam buku When Culture Collide.

[6] Raymer, Daniel, 1989, Aircraft Design, AIAA Education Series, Washington.

[7] http://www.centennialofflight.gov/essay/Air_Power/Pre_WWI/AP1.htm14 nov07. 